\title{
Osmotic demyelination syndrome in a patient with Noonan syndrome and anterior hypopituitarism
}

\author{
Tzy Harn Chua and Wann Jia Loh
}

Department of Endocrinology, Changi General Hospital, Singapore

Correspondence should be addressed to T Chua

Email

tzyharn.chua@mohh.com.sg

\section{Summary}

Severe hyponatremia and osmotic demyelination syndrome (ODS) are opposite ends of a spectrum of emergency disorders related to sodium concentrations. Management of severe hyponatremia is challenging because of the difficulty in balancing the risk of overcorrection leading to ODS as well as under-correction causing cerebral oedema, particularly in a patient with chronic hypocortisolism and hypothyroidism. We report a case of a patient with Noonan syndrome and untreated anterior hypopituitarism who presented with symptomatic hyponatremia and developed transient ODS.

\section{Learning points:}

- Patients with severe anterior hypopituitarism with severe hyponatremia are susceptible to the rapid rise of sodium level with a small amount of fluid and hydrocortisone.

- These patients with chronic anterior hypopituitarism are at high risk of developing ODS and therefore, care should be taken to avoid a rise of more than 4-6 $\mathrm{mmol} / \mathrm{L}$ per day.

- Early recognition and rescue desmopressin and i.v. dextrose $5 \%$ fluids to reduce serum sodium concentration may be helpful in treating acute ODS.

\section{Background}

Severe hyponatremia increases morbidity and mortality. Management of hyponatremia depends on the chronicity of hyponatremia to avoid the risk of osmotic demyelination syndrome (ODS) from overly quick correction while balancing the potential detrimental effects of severe hyponatremia which itself can lead to seizures, arrhythmia and death (1). For cases with undetermined chronicity of hyponatremia, the rate of correction has been recommended at not more than 10 $\mathrm{mmol} / \mathrm{L}$ per first $24 \mathrm{~h}$ or $18 \mathrm{mmol} / \mathrm{L}$ for the next $48 \mathrm{~h}$, and even slower rate of correction for patients at higher risk of ODS $(1,2,3)$. However, despite correction of hyponatremia in accordance with guidelines, ODS can still occur $(4,5)$. We report a case of chronic hyponatremia secondary to severe anterior hypopituitarism in a patient with clinical features of Noonan's syndrome. There was a complication of transient ODS which resolved due to quick actions taken to reduce further rise in sodium concentration.

\section{Case presentation}

A 50-year-old male presented to the emergency department with 2-day history of insomnia, severe nausea and dizziness. This was associated with a generalised dull headache. He denied any other neurological symptoms and weight loss. A thorough history taking revealed that he was diagnosed with 'hormonal deficiency' when he was 35 years old. He took oral hormonal replacement for 1-2 years and then defaulted follow up and treatment because he felt well. He was unable to recall the presenting 
complaints that made him present to hospital, the details of his medications and tests performed then. These medical records were unavailable. At 42 years old, he presented to the hospital with abdominal pain and vomiting. A review of his old medical records revealed that his serum sodium concentration levels were significantly low at 101-105 $\mathrm{mmol} / \mathrm{L}$ at that point. He received inpatient i.v. fluids and was initiated on hormonal replacement levothyroxine and hydrocortisone. MRI of the pituitary fossa showed a nonenhancing $2 \mathrm{~mm}$ lesion in the left pituitary gland with an impression of possibly a non-functioning micro-adenoma. He was discharged from inpatient stay against medical advice when he was asymptomatic, and sodium concentration was $105 \mathrm{mmol} / \mathrm{L}$. A recheck sodium concentration outpatient 2 weeks later showed that it normalised at $135 \mathrm{mmol} / \mathrm{L}$. He admittedly took the medications for a year only and again stopped because he was feeling well and was very poor. He defaulted the doctor's follow up and did not take hormonal replacements since then. He denied taking any regular medications, including diuretics or psychotropics. He did not have any repeat blood test since then. There was no available information about his growth and development in childhood. He came from a poor family with low socioeconomic status.

Interestingly, despite having hypocortisolism and hypothyroidism, possibly for the last two decades, he was working full-time as a logistics assistant in an elementary school. His job scopes were simple repairs, cleaning and carrying things. His favourite pastime was playing simple computer games. He lived with a sibling who provided food and lodging for him. He did not smoke and did not drink alcohol. He never had any sexual interest, thoughts and did not remember his last erection or whether he had one before. He had a few friends and was a quiet person.

In the emergency department, he was afebrile, heart rate of 57 b.p.m., respiratory rate of 16 breaths per minutes and blood pressure of $119 / 58 \mathrm{mmHg}$ and $\mathrm{SpO}_{2}$ of $100 \%$ on room air. Despite an initial drip of $500 \mathrm{~mL}$ of normal saline prescribed by the emergency doctor, he was hypotensive the next morning with a blood pressure of 90/50 $\mathrm{mmHg}$. Physical examination of the heart, lungs, abdomen and neurological system was unremarkable. However, he was noticeable for his smooth, young-looking facial skin, hairless face, absence of pubic and axillary hair and severe kyphoscoliosis of the thoracolumbar spine. Gynecomastia was present bilaterally, both testes were very small at less than $5 \mathrm{~mL}$ in volume each and his penile length was short at $5 \mathrm{~cm}$. He did not have hypospadias. He had clinical features of Noonan syndrome which were short height $(1.6 \mathrm{~m})$, low set ears, a short neck, webbed neck, wide

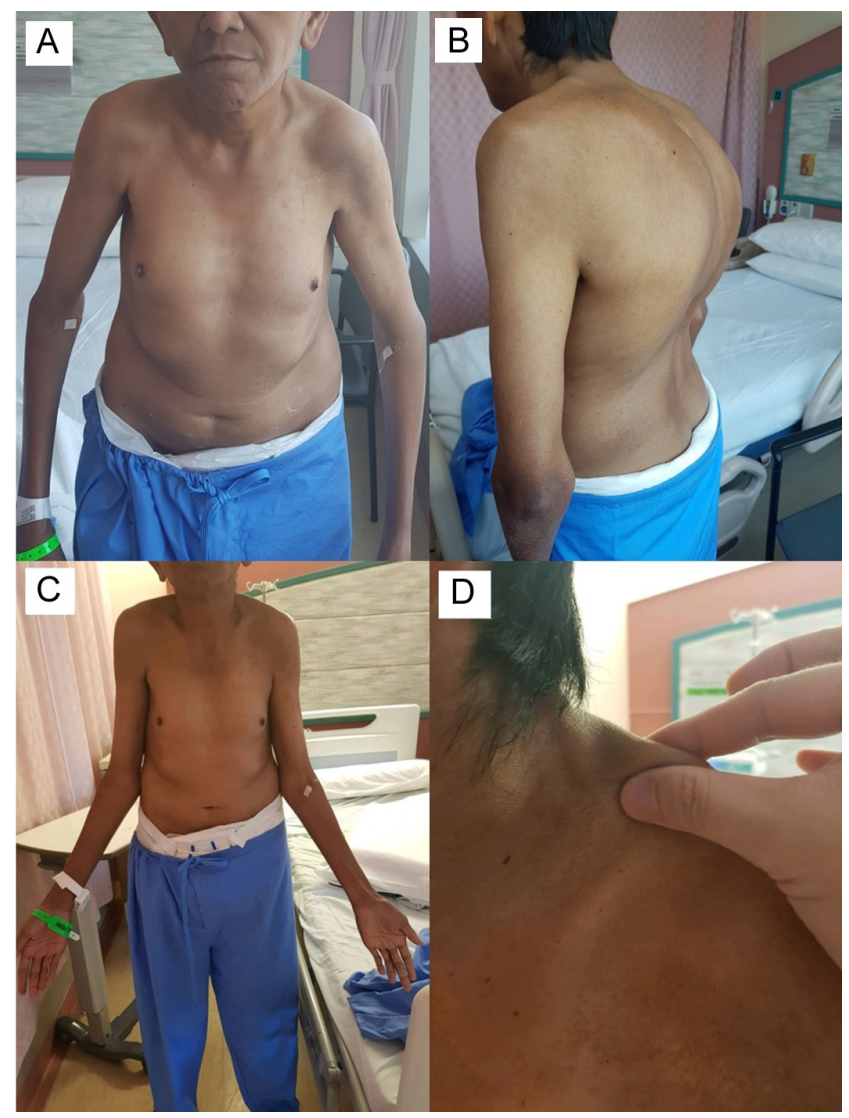

\section{Figure 1}

The patient had features of Noonan syndrome and hypogonadism as shown in the pictures for (A) gynecomastia, (B) severe kyphoscoliosis, (C) widened cubital fossa and (D) webbed neck.

carrying angle of the elbows, and severe kyphoscoliosis (Fig. 1) (6). He did not have a cleft palate, hypotelorism or any facial signs of midline defect.

\section{Investigation}

This patient had hypo-osmolar hyponatremia with a serum sodium of $109 \mathrm{mmol} / \mathrm{L}$, low serum osmolality of $229 \mathrm{mOsm} / \mathrm{kg}$, urine sodium of $181 \mathrm{mmol} / \mathrm{L}$ and urine osmolality of $631 \mathrm{mOsm} / \mathrm{kg}$. Endocrinological evaluation showed that he had anterior hypopituitarism, causing hypocortisolism, hypothyroidism, hypogonadism, and low growth hormone levels (Table 1). His free thyroxine $\mathrm{T} 4$ and free T3 levels were low at 6.45 and $2.03 \mathrm{pmol} / \mathrm{L}$, respectively, with an inappropriately normal serum TSH of $4.28 \mathrm{mIU} / \mathrm{L}$ suggesting central hypothyroidism. During morning ward rounds by the primary team (i.e. day 2 ), blood test (08:00 h) was sent off immediately for serum cortisol which returned as very low at $86 \mathrm{nmol} / \mathrm{L}$ with an inappropriately normal serum ACTH of $35.5 \mathrm{ng} / \mathrm{L}$ 
Table 1 Blood tests, hormonal results and urine tests of the patient.

\begin{tabular}{|c|c|c|}
\hline Investigations & Patient & Reference range \\
\hline \multicolumn{3}{|l|}{ Blood tests } \\
\hline Sodium (mmol/L) & 109 & $135-145$ \\
\hline Osmolality (mOsm/kg) & 229 & $275-300$ \\
\hline Potassium (mmol/L) & 4.0 & $3.5-5.3$ \\
\hline Chloride (mmol/L) & 77 & $96-108$ \\
\hline Glucose (mmol/L) & 4.7 & $3.1-7.8$ \\
\hline Albumin (g/L) & 50 & $37-51$ \\
\hline 25-Hydroxyvitamin D ( $\mu \mathrm{g} / \mathrm{L})$ & 19.3 & $30.0-100.0$ \\
\hline Haemoglobin (g/dL) & 12.0 & $13.0-17.0$ \\
\hline White cells $\left(\times 10^{3} / \mu \mathrm{L}\right)$ & 5.4 & $4.0-10.0$ \\
\hline \multicolumn{3}{|l|}{ Serum hormones } \\
\hline Free T4 (pmol/L) & 6.45 & $10.00-20.00$ \\
\hline Free T3 (pmol/L) & 2.03 & $2.50-5.50$ \\
\hline $\mathrm{TSH}(\mathrm{mIU} / \mathrm{L})$ & 4.28 & $0.400-4.00$ \\
\hline Cortisol (08:00 h) (nmol/L) & 86 & $170-500$ \\
\hline ACTH (ng/L) & 35.5 & $10.0-60.0$ \\
\hline Testosterone (nmol/L) & $<0.400$ & $9.900-27.80$ \\
\hline FSH (U/L) & 0.40 & $1.00-12.00$ \\
\hline $\mathrm{LH}(\mathrm{IU} / \mathrm{L})$ & $<0.50$ & $0.57-12.07$ \\
\hline SHBG (nmol/L) & 114.1 & $15.0-50.0$ \\
\hline Fasting 09:00 h GH ( $\mu \mathrm{g} / \mathrm{L})$ & 0.06 & \\
\hline IGF-1 ( $\mu \mathrm{g} / \mathrm{L})$ & $<25$ & $48-209$ \\
\hline Prolactin (mIU/L) & 213.7 & $73.0-407.0$ \\
\hline PTH (intact) (pmol/L) & 2.84 & $1.30-7.60$ \\
\hline \multicolumn{3}{|l|}{ Urine test } \\
\hline Paired sodium (mmol/L) & 181 & $40-220$ \\
\hline Paired osmolality (mOsm/kg) & 631 & \\
\hline
\end{tabular}

TSH, thyroid stimulating hormone; ACTH, adrenocorticotropic hormone, FSH, follicle stimulating hormone; Lh, luteinising hormone; SHBG, sex hormone binding globulin; GH, growth hormone; PTH, parathyroid hormone

indicating a central hypocortisolism state. The first dose of hydrocortisone was immediately given after the serum cortisol was taken but while awaiting the results, in view of the high clinical suspicion for hypocortisolism. He also had central hypogonadism as evidenced by a low serum total testosterone $(<0.400 \mathrm{nmol} / \mathrm{L})$, a low FSH $(0.40 \mathrm{U} / \mathrm{L})$, a low $\mathrm{LH}<0.50 \mathrm{IU} / \mathrm{L}$. His serum IGF-1 was low $(<25 \mu \mathrm{g} / \mathrm{L})$. A repeat testing of fasting morning GH and IGF-1 levels at 3 months times showed persistently low and undetectable readings, suggesting growth hormone deficiency. Serum prolactin was normal at $213.7 \mathrm{mIU} / \mathrm{L}$. He did not have central diabetes insipidus.

His spine X-ray showed marked kyphosis of the thoracic spine as well as lumbar scoliosis with convexity towards the left. There was no loss of vertebral height loss although his bone mineral density showed osteoporosis with $T$ score -3.5 of the left femoral neck $(0.472 \mathrm{~g} /$ $\left.\mathrm{cm}^{2}\right), T$ score of -3.2 of the left hip $\left(0.592 \mathrm{~g} / \mathrm{cm}^{2}\right)$ and $T$ score of -3.1 of the lumbar spine $\left(0.641 \mathrm{~g} / \mathrm{cm}^{2}\right)$. His osteoporosis is likely caused by prolonged untreated

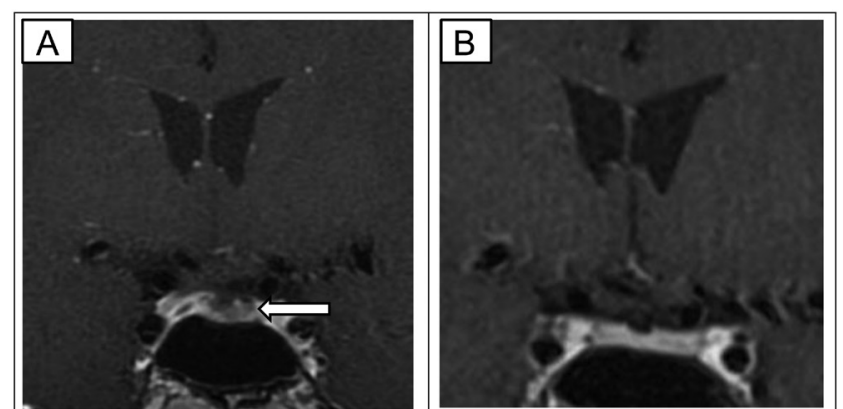

\section{Figure 2}

MRI pituitary scans with sequences using Coronal T1 weighted with contrast showed: (A) pituitary microadenoma of $8 \mathrm{~mm}$ (white arrow) 8 years ago and (B) normal pituitary.

hypogonadism and growth hormone deficiency. His ECG and echocardiogram tests were normal. He did not have any cardiac manifestations of Noonan syndrome, such as hypertrophic cardiomyopathy, pulmonary stenosis and atrial septal defects $(6,7)$. MRI pituitary revealed a normal pituitary and pituitary stalk (Fig. 2). The previously noted pituitary adenoma 8 years ago was no longer seen (Fig. 2). MRI brain performed was normal without any midline defect seen. These scans were performed inpatient after the patient had his seizure which is described subsequently.

\section{Treatment}

The acute management of his hyponatremia where he presented to at night to emergency department included i.v. normal saline (i.e. $0.9 \% \mathrm{NaCl}$ ) drip because he was symptomatic with dizziness, nausea and lethargy. By the next morning, that is within $12 \mathrm{~h}$, the endocrine workup was performed, and his limited old medical records were reviewed by the inpatient medical team, leading to a diagnosis of chronic untreated anterior hypopituitarism, as well as a clinical diagnosis of Noonan syndrome. Caution was taken to increase his sodium level slowly yet surely, in order to improve his symptoms. Serum sodium was measured every $4-6 \mathrm{~h}$. In the first $22 \mathrm{~h}$ of admission, he received $500 \mathrm{~mL}$ of $0.9 \% \mathrm{NaCl}$ fluid and a single dose of i.v. $100 \mathrm{mg}$ of hydrocortisone and his serum sodium increased by $4 \mathrm{mmol} / \mathrm{L}$, from 109 to $113 \mathrm{mmol} / \mathrm{L}$. In the subsequent $15 \mathrm{~h}$, despite only receiving $150 \mathrm{~mL}$ of $\mathrm{NaCl}$, his serum sodium level increased by $10 \mathrm{mmol} / \mathrm{L}$, from 113 to $123 \mathrm{mmol} / \mathrm{L}$ (Fig. 3). Because his vitals were stable and symptoms improved, after the single dose of i.v. hydrocortisone, this was changed to oral hydrocortisone. A low dose of levothyroxine was started the following day and titrated upwards gradually. The aim now was to avoid further rapid rise of his serum sodium level, and his 


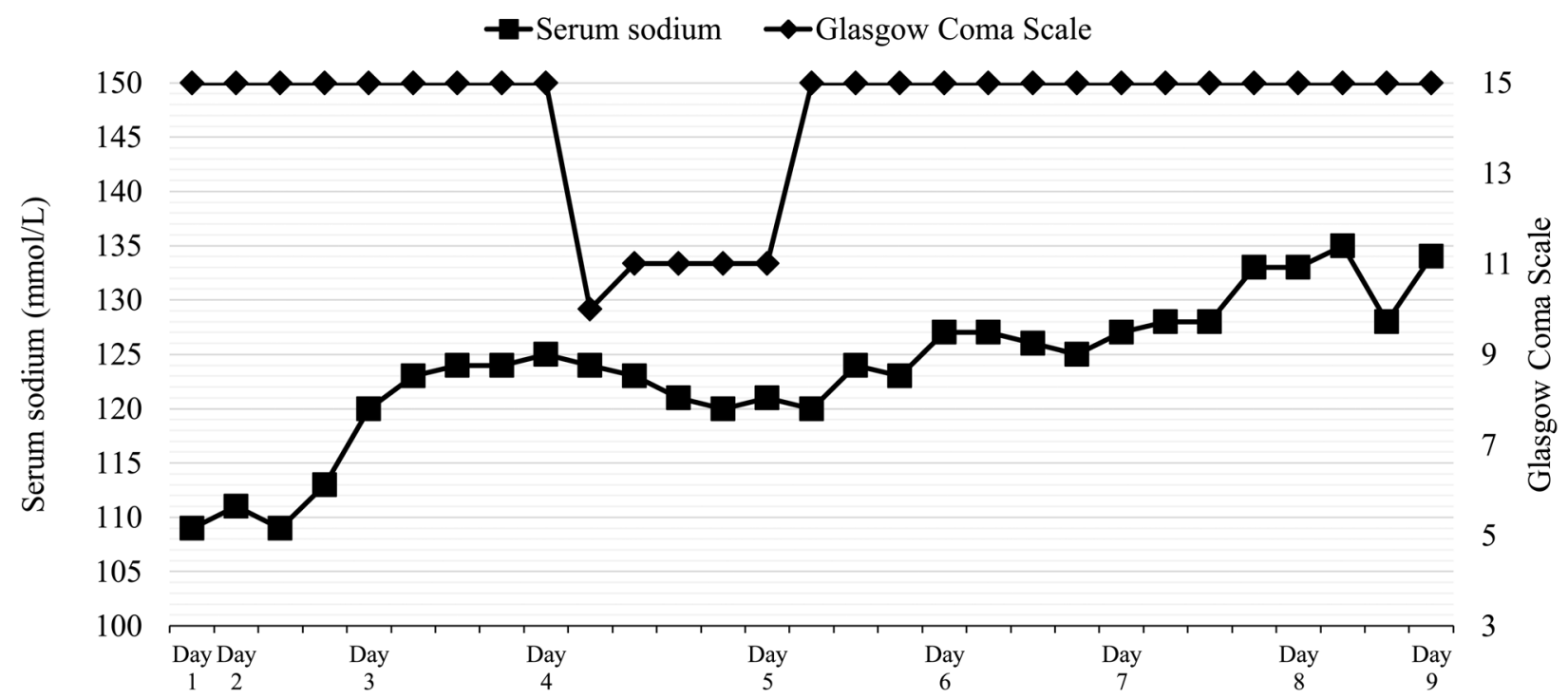

\begin{tabular}{|c|c|c|c|c|c|c|c|c|c|}
\hline IV fluids & $\begin{array}{c}500 \\
\mathrm{ml} \\
\mathrm{NS}\end{array}$ & $\begin{array}{c}150 \mathrm{ml} \\
\text { Normal } \\
\text { Saline(NS) }\end{array}$ & $\begin{array}{c}1000 \mathrm{ml} \\
5 \% \text { dextrose }\end{array}$ & $\begin{array}{c}1000 \mathrm{ml} 5 \% \\
\text { dextrose }\end{array}$ & $\begin{array}{c}500 \mathrm{ml} 5 \% \\
\text { dextrose }\end{array}$ & \multicolumn{4}{|c|}{$1000 \mathrm{ml} 5 \%$ dextrose per day } \\
\hline $\begin{array}{l}\text { Hydrocortisone } \\
\text { (route, dose) }\end{array}$ & - & $\begin{array}{l}\text { IV } 100 \mathrm{mg} \\
\text { PO 20mg }\end{array}$ & PO 20mg & PO 10mg & $\begin{array}{l}\text { IV } 25 \mathrm{mg} \\
\text { PO } 5 \mathrm{mg}\end{array}$ & \multicolumn{4}{|c|}{ PO 20mg x 2 doses per day } \\
\hline $\begin{array}{l}\text { Thyroxine } \\
\text { (route, dose) }\end{array}$ & - & - & PO 50mcg & - & PO $50 \mathrm{mcg}$ & \multicolumn{4}{|c|}{ PO 50mcg per day } \\
\hline $\begin{array}{l}\text { Desmopressin } \\
\text { (route, dose) }\end{array}$ & - & - & - & IV $1 \mathrm{mcg}$ & - & IV $1 \mathrm{mcg}$ & - & - & - \\
\hline
\end{tabular}

Figure 3

The trend of serum sodium concentration and Glasgow Coma Scale of the patient during his hospital stay. Various fluids and medications given at specific time points are illustrated. PO, peroral.

sodium level was maintained at $123-125 \mathrm{mmol} / \mathrm{L}$ in the next 24 h (days 3-4 of admission).

However, despite these efforts, he developed an acute episode of hypertonia and aphasia (GCS level E4V1M5) on day 4 when his serum sodium level was $124 \mathrm{mmol} / \mathrm{L}$. On examination, he was alert, eyes open but unable to speak, with significantly increased tone in upper limbs and drooling evident. MRI of the brain performed within the next $2 \mathrm{~h}$ was normal. He also had an episode of partial seizure with witnessed repetitive movements of his right arm, lasting for approximately $3 \mathrm{~min}$, which terminated spontaneously. He was prescribed antiepileptic agent sodium valproate to prevent further seizures. To reduce his serum sodium level, i.v. $1 \mu \mathrm{g}$ of desmopressin and i.v. dextrose $5 \%$ fluids were given. His serum sodium level was successfully reduced to $120-122 \mathrm{mmol} / \mathrm{L}$ over the next few hours, with complete neurological recovery the next day (day 5 of admission). His serum sodium level was closely monitored with the aim of a rise of not more than $5 \mathrm{mmol} / \mathrm{L} /$ day until normalisation of his serum sodium level to $135 \mathrm{mmol} / \mathrm{L}$ (Fig. 3). Another repeat MRI of the brain (day 5 of admission) was again normal and did not show signs of osmotic demyelination. Although, radiological signs of demyelinating lesions can be delayed at about 5 days after ODS (8), no further MRI scans were performed as he had completely recovered.

\section{Outcome and follow-up}

This patient was reviewed in the endocrinology outpatient clinic at 1, 3 and 6 months after hospital discharge. He was alert, jovial and talkative, unlike his previous self. His serum sodium and serum-free T4 levels were normal. He was also commenced on testosterone replacement therapy. The chronic management of this patient included education of adherence of hormonal replacement hydrocortisone and levothyroxine. Advice to increase hydrocortisone dose on sick days was frequently emphasised to him and his family. With the help of our medical social worker, the patient did not have to worry about financial payment for his medical treatment and he was able to obtain appropriate medical care through government's subsidy. This helped to prevent further default of medical follow up. 


\section{Discussion}

We reported a case of Noonan syndrome, that presented with chronic severe hyponatremia secondary to severe anterior hypopituitarism. This case has a few interesting points. This patient survived and worked many years with severe hyponatremia, hypocortisolism and hypogonadism despite presenting with a few admissions for symptomatic severe hyponatremia. He never suffered from hypocortisolic crisis, myxedema coma or cerebral oedema before. This case report showed that quick action to lower sodium level could avoid permanent ODS sequelae. This case report also adds to the rarely described cases of patients with Noonan syndrome and hypopituitarism in the literature $(9,10)$.

Usually, patients with Noonan syndrome present with growth issues including short stature and delayed puberty (7). This is likely to be related to genetic defects in the RASMAPK (mitogen-activated protein kinase) pathway (7). Mutations of PTPN11, SOS1, RAF1, MEK1 and RAS have been detected in Noonan Syndrome with PTPN11 mutations being the most common (7). While these mutations have not been directly associated with hypopituitarism, PTPN11 protein product SHP-2 (Src homology region 2-domain phosphatase 2) is a cytoplasmic protein with tyrosine phosphatase actions which is important in the signalling pathway of growth factors, IGF-1, insulin, leptin and cytokines (7). Therefore, mutation such as of PTPN11 or yet-to-be identified mutations could account for the concomitant hypopituitarism in this patient, however, this is speculative as genetic testing was not performed in this case.

Chronic hypocortisolism, severe hyponatremia and chronic hyponatremia increased his risk of having ODS. Low levels of cortisol fail to suppress vasopressin, resulting in impaired excretion of free water (3). When cortisol level is replaced, this leads to inhibition of vasopressin and increases the free water excretion leading to sodium concentration rising. Neurological impairments due to ODS are caused by brain dehydration leading to shrinkage of brain cells. In our case, although the rise of serum sodium concentration was only $14 \mathrm{mmol} / \mathrm{L}$ over $48 \mathrm{~h}$, the abrupt rise during days 2-3 from the water diuresis from hydrocortisone replacement as well as the use of a small amount of $\mathrm{NaCl}$ precipitated the episode of ODS. Other risk factors associated with a higher risk of developing ODS are alcohol abuse, liver disease, use of thiazides and/ or antidepressants (3). Poor insight and understanding of the importance of hormone replacement adherence can lead to devastating consequences. Hypopituitarism, in particular, glucocorticoid deficiency is an important cause of hyponatremia and hypocortisolism crisis $(1,2$, $3)$. Patient education, especially in conditions of chronic hormonal deficiencies is key in ensuring patients remain adherent to treatment.

ODS is commonly observed in patients with chronic severe hyponatremia that has been corrected by $>10-12$ $\mathrm{mmol} / \mathrm{L}$ per day or $>18 \mathrm{mmol} / \mathrm{L}$ in $48 \mathrm{~h}$ (11). However, ODS was also reported in patients whose chronic hyponatraemia was corrected at a recommended rate (4, 5). To avoid ODS, correction of chronic hyponatremia at a rate of $<12 \mathrm{mmol} / \mathrm{L} /$ day was recommended as early as 1986 (12). Subsequently, experts suggest that a correction rate of 4-6 mmol/L/day is sufficient for both acute and chronic hyponatremia (11). However, the optimal rate of correction is controversial. A systematic review revealed a total of eight guidelines that recommended varying rates of correction between 8 and $12 \mathrm{mmol} / \mathrm{L}$ per day, as well as different doses of normal saline and infusion speed (2). In cases of severe symptomatic hyponatremia, undercorrection of serum sodium levels leads to morbidity and hypertonic saline would generally be first-line treatment (2). As seen in our case, it is judicious to correct serum sodium slowly, especially when given hydrocortisone replacement, which can increase the serum sodium levels much more than intended or expected (11). Although hydrocortisone itself without i.v. normal saline may be sufficient to improve hyponatremia in a hypocortisolic patient who is drinking orally, this patient was necessarily prescribed the i.v. normal saline in view of his symptoms of dizziness, nausea, and hypotension in the ward. The management can be challenging as the extent of sodiumraising effect of hydrocortisone is not quite predictable.

Desmopressin has been shown to reduce the rate of serum sodium correction from 0.81 to $-0.02 \mathrm{mmol} /$ $\mathrm{L} / \mathrm{h}$, and reduce the magnitude of variation of serum sodium levels (13). While a systematic review showed that while proactive approach with desmopressin was shown to be associated with a lower incidence of overcorrection of serum sodium (14), reactive approach has also been favoured by others (15), and thus, it remains undetermined when desmopressin should optimally be given $(9,10)$. Although the prognosis of ODS is better than previously thought with about half of the patients having favourable outcomes, the same study showed that about $30 \%$ of patients admitted to intensive care died at 1-year follow-up. This highlights the importance of avoiding ODS (16). The management of chronic hyponatremia should be individualised depending on the clinical picture and circumstances. 


\section{Patient's perspective}

I felt more energetic and alert after several months of hormonal replacement. I am working full-time, as well. My family and friends have also noted the improved difference in me. They said that I am more energetic, cheerful, and active than previously.

\section{Declaration of interest}

The authors declare that there is no conflict of interest that could be perceived as prejudicing the impartiality of the research reported.

\section{Funding}

This research did not receive any specific grant from any funding agency in the public, commercial or not-for-profit sector

\section{Patient consent}

Written informed consent has been obtained from the patient for publication of this article and the accompanying images.

\section{Author contribution statement}

W J L was the primary physician of the patient. T H C and $W \mathrm{~J} L$ managed the patient, wrote the manuscript and approved the final version of the manuscript.

\section{References}

1 Verbalis JG, Goldsmith SR, Greenberg A, Schrier RW \& Sterns RH. Hyponatremia treatment guidelines 2007: expert panel recommendations. American Journal of Medicine $2007 \mathbf{1 2 0}$ (Supplement 1) S1-S21. (https://doi.org/10.1016/j.amjmed.2007.09.001)

2 Nagler EV, Vanmassenhove J, van der Veer SN, Nistor I, Van Biesen W, Webster AC \& Vanholder R. Diagnosis and treatment of hyponatremia: a systematic review of clinical practice guidelines and consensus statements. BMC Medicine 201412 1. (https://doi. org/10.1186/s12916-014-0231-1)

3 Spasovski G, Vanholder R, Allolio B, Annane D, Ball S, Bichet D, Decaux G, Fenske W, Hoorn EJ, Ichai C, et al. Clinical practice guideline on diagnosis and treatment of hyponatraemia. European Journal of Endocrinology $2014 \mathbf{1 7 0}$ G1-G47. (https://doi.org/10.1530/ EJE-13-1020)

4 Dellabarca C, Servilla KS, Hart B, Murata GH \& Tzamaloukas AH. Osmotic myelinolysis following chronic hyponatremia corrected at an overall rate consistent with current recommendations. International Urology and Nephrology 200537 171-173. (https://doi. org/10.1007/s11255-004-4770-9)

5 Georgy V, Mullhi D \& Jones AF. Central pontine myelinolysis following 'optimal' rate of correction of hyponatraemia with a good clinical outcome. Annals of Clinical Biochemistry 200744 488-490. (https://doi.org/10.1258/000456307781646067)

6 Bhambhani V \& Muenke M. Noonan syndrome. American Family Physician 201489 37-43.

7 Jorge AA, Malaquias AC, Arnhold IJ \& Mendonca BB. Noonan syndrome and related disorders: a review of clinical features and mutations in genes of the RAS/MAPK pathway. Hormone Research 200971 185-193. (https://doi.org/10.1159/000201106)

8 Sterns RH, Thomas DJ \& Herndon RM. Brain dehydration and neurologic deterioration after rapid correction of hyponatremia. Kidney International 198935 69-75. (https://doi.org/10.1038/ ki.1989.9)

9 Couser NL, Keelean-Fuller D, Davenport ML, Haverfield E, Masood MM, Henin M \& Aylsworth AS. Cleft palate and hypopituitarism in a patient with Noonan-like syndrome with loose anagen hair-1. American Journal of Medical Genetics: Part A $2018 \mathbf{1 7 6}$ 2024-2027. (https://doi.org/10.1002/ajmg.a.40432)

10 Ross JL \& Shenkman L. Noonan's syndrome and hypopituitarism. American Journal of the Medical Sciences 1980279 47-52. (https://doi. org/10.1097/00000441-198001000-00006)

11 Sterns RH, Hix JK \& Silver SM. Management of hyponatremia in the ICU. Chest 2013144 672-679. (https://doi.org/10.1378/chest.122600)

12 Sterns RH, Riggs JE \& Schochet Jr SS. Osmotic demyelination syndrome following correction of hyponatremia. New England Journal of Medicine 1986314 1535-1542. (https://doi.org/10.1056/ NEJM198606123142402)

13 Rafat C, Schortgen F, Gaudry S, Bertrand F, Miguel-Montanes R, Labbe V, Ricard JD, Hajage D \& Dreyfuss D. Use of desmopressin acetate in severe hyponatremia in the intensive care unit. Clinical Journal of the American Society of Nephrology 20149 229-237. (https:// doi.org/10.2215/CJN.00950113)

14 MacMillan TE, Tang T \& Cavalcanti RB. Desmopressin to prevent rapid sodium correction in severe hyponatremia: a systematic review. American Journal of Medicine 2015128 1362.e15-1362.e24. (https:// doi.org/10.1016/j.amjmed.2015.04.040)

15 MacMillan TE \& Cavalcanti RB. Outcomes in severe hyponatremia treated with and without desmopressin. American Journal of Medicine 2018131 317.e1-317.e10. (https://doi.org/10.1016/j. amjmed.2017.09.048)

16 Louis G, Megarbane B, Lavoue S, Lassalle V, Argaud L, Poussel JF, Georges $\mathrm{H} \&$ Bollaert PE. Long term outcome of patients hospitalised in intensive care units with central or extrapontine myelinolysis. Critical Care Medicine 201240 970-972. (https://doi.org/10.1097/ CCM.0b013e318236f152)

Received in final form 18 May 2020

Accepted 29 July 2020 